\title{
Sistem Pengingat Ganti Oli Berdasarkan Running Hours Mesin, Lama Waktu Pemakaian dan Kekentalan Oli pada Mesin Wire Drawing Berbasis Raspberry Pi 1
}

\author{
Riza Samsinar ${ }^{1}$, Eko Priatna ${ }^{2}$, Deni Almanda ${ }^{3}$ \\ 1,2,3) Teknik Elektro Universitas Muhammadiyah Jakarta \\ Jl. Cempaka Putih Tengah 27 No 47 \\ E-mail: riza.samsinar@ftumj.ac.id
}

\begin{abstract}
ABSTRAK
Pada perkembangan teknologi saat ini perusahaan - perusahaan semakin gencar untuk mendatangkan mesin - mesin dengan teknologi - teknologi cangih dan modern, sehingga perusahaan pun semakin ketat untuk dapat menghasilkan produk - produk dengan kualitas dan mutu yang baik dan tepat sasaran serta efektif dan efesien. Untuk mencapai itu semua perlu adanya perawatan terhadap mesin - mesin produksi agar performa mesin produksi tetap terjaga dengan baik, salah satu perawatan mesin adalah dengan cara mengganti oli secara berkala dengan ditambahkan sistem pengingat ganti oli berdasarkan running hours mesin, lama waktu pemakaian dan kekentalan oli pada mesin wire drawing berbasis raspberry pi. Ada 3 parameter pada sistem pengingat ganti oli yaitu: berdasarkan running hours, lama waktu pemakian dan kekentalan oli, dari tiga parameter tersebut jika salah satu atau semua sudah mencapai parameter seting yang ditentukan disetiap oli, maka oli di nyatakan tidak layak pakai dan harus segera diganti, dan semua parameter dan hasil dapat dilihat pada LCD dan buzzer sebagai penanda bunyi jika oli sudah harus segera diganti. Dengan adanya pergantian oli secara berkala maka kerusakan - kerusakan mesin yang di akibatkan gearbox mesin yang pecah dapat dihilangkan, sehingga mesin dapat menghasilkan produk - produk yang berkualitas dan tidak menimbulkan downtime mesin yang dapat menggangu aktifitas produksi secara efektif dan efesien.
\end{abstract}

\section{Kata kunci: Raspberry Pi, LCD, Wire Drawing, Perawatan Mesin}

\section{PENDAHULUAN}

Seiring perkembangan teknologi dan kesibukan seseorang yang semakin bertambah, sering kali seseorang lupa atau terlewat dari waktu standartnya untuk mengganti oli mesin produksi, hal itu dikarenakan belum adanya sistem reminder/pengingat untuk penggantian oli mesin produksi disebuah perusahaan, mengakibatkan mesin produksi cepat rusak atau bermasalah. Pada saat ini dalam mengganti oli, bagian maintenance di PT IWWI hanya berdasarkan pada warna oli saja, bening atau sudah menghitam. Dan pada tahun 2016 didapat data kerusakan mesin diakibatkan gearbox yang hancur karena kualitas oli yang buruk karena tidak secara berkala dilakukan pergantian oli pada mesin gearbox. Dari latar belakang tersebut perlu dibuatkan sistem reminder/pengingat ganti oli berdasarkan kualitas oli mesin. Biasanya kualitas oli ditentukan brdasarkan running hours mesin, kekentalan oli yang diukur dengan cara mengukur banyaknya putaran mesin pada pengaduk oli atau berdasarkan lama waktu pemakaian oli. Dengan demikian pengguna bisa mengganti oli secara teratur dan mesin produksi akan menjadi lebih terpelihara. Berdasarkan latar belakang masalah d iatas, maka masalah dapat di identifikasikan menjadi bagaimana cara mendesain dan membuat "sistem pengingat ganti oli berdasarkan running hours mesin, lama waktu pemakaian \& kekentalan oli pada mesin wire drawing berbasis raspberry pi 1"? dan bagaimana cara membuat rangkaian sensor untuk mendeteksi kekentalan oli?

Untuk mengindari timbulnya masalah baru yang tidak sesuai dengan tujuan dari penelitian ini maka perlu adanya batasan - batasan, diantaranya penulis mengimplementasikan sebuah sistem reminder atau pengingat ganti oli mesin produksi pada sebuah mesin wire drawing, sistem ini akan bekerja mengingatkan berdasarkan running hours mesin, kekentalan oli dan waktu pemakaian oli pada mesin wire drawing, Perancangan sensor infrared dan photodiode sebagai pembaca putaran pengaduk oli dan pembacaan running hours mesin, display LCD, dan ditandakan dengan suara dan sebagai pengingat bahwa oli mesin produksi tersebut sudah saatnya untuk diganti, push button untuk pemilihan menu dan pemilihan ganti oli jika telah selesai melakukan penggantian oli mesin. Tujuan dari pembuatan penelitian ini adalah Sebagai pengingat pergantian oli mesin produksi yang diukur berdasarkan running hours mesin, kekentalan oli, dan lama waktu pemakaian oli, menerapkan ilmu yang telah dipelajari 
selama mengikuti perkuliahan dalam bentuk penelitian dan membuat "Sistem Pengingat Ganti Oli Berdasarkan Running Hours Mesin, Lama Waktu Pemakaian \& Kekentalan Oli Pada Mesin Wire Drawing Berbasis Raspberry Pi dan mengembangkan ilmu pengetahuaan dibidang mekanik, elektrik dan kontrol yang mampu memberikan manfaat bagi manusia. Seperti semua teknologi, robot melaksanakan tugas yang telah teridealisasi [1]. Pada saat ini kebutuhan akan daya listrik merupakan hal yang mutlak, untuk itu perlu diadakan adanya monitoring kebutuhan daya listrik agar pengeluaran akan kebutuhan litrik bisa terpantau dengan mudah [2]. Viskositas merupakan salah satu indikator penting untuk mengetahui pelumas dalam kondisi layak atau tidak [3]. Energi menjadi salah satu isu yang dihadapi oleh Indonesia saat ini bahkan dunia, karena ketidakseimbangan antara ketersediaan energi dengan kebutuhanya [4]. Teknik elektro merupakan salah satu dari ilmu teknik dasar yang merupakan komponen esensial dari perkembangan ilmu pengetahuan alam dan teknologi [5]. Didalam sistem jaringan distribusi listrik lokal (local grid) yang kita mengenal istilah microgrid dan nanogrid yang terkenal untuk pembangkit listrik yang berdiri sendiri [6]. Mengerjakan proyek tepat waktu sesuai dengan biaya, lingkup pekerjaan, serta mutu yang sudah ditetapkan menjadi target setiap perusahaan [7]. Energi listrik merupakan salah satu kebutuhan pokok yang sangat penting dalam kehidupan manusia saat ini, hampir semua aktifitas manusia berhubungan dengan energi listrik [8, p. 6]. Dihunian yang modern saat ini, tak sedikit pula rumah yang memiliki kamera cctv untuk mendukung keamanan rumahnya [9]. Pengukuran adalah suatu pembandingan antara suatu besaran dengan besaran lain yang sejenis secara eksperimen dan salah satu besaran dianggap sebagai standar [10]. Iradiasi surya biasanya diukur dengan solarimeter yang ditempatkan pada permukaan datar [11]. Transistor efek medan berbasis semikonduktor organik bisa dimanfaatkan untuk sensor kelembaban [12]. Intensitas radiasi cahaya matahari yang diterima sel surya sebanding dengan tegangan dan arus listrik yang dihasilkan oleh sel surya [13]. Sepeda motor merupakan kendaraan yang lazim digunakan oleh semua kalangan; mulai dari kalangan atas, menengah, sampai kalangan bawah [14]. Untuk dapat mendayai suatu beban listrik dengan baik, dalam hal ini merupakan rumah kaca, diperlukan desain sistem yang baik pula [15]. Ada banyak sumber energi terbarukan seperti energi air, energi angin dan energi matahari [16]. PLTH ini dioperasikan untuk memikul beban [17]. Energi sangat penting untuk manusia untuk bisa bertahan hidup [18]. Perkembangan dibidang ilmu pengetahuan dan teknologi memiliki kemajuan yang sangat pesat yang berdampak pada kehidupan kita saat ini [19]. Transistor film tipis organik memiliki potensi untuk penggunaan pada aplikasi elektronika yang biayanya rendah, permukaannya luas, ringan dan fleksibel [20]. Rangkaian penyearah gelombang penuh adalah penyearah yang mengonversikan kedua siklus positif dan negative dari sinyal AC menjadi sinyal DC yang berdenyut [21]. Tegangan sirkuit terbuka akan bertambah jika sel sel surya dihubungkan secara seri [22]. Material organik telah menjadi perhatian para peneliti meskipun karakternya kurang dari silikon [23]. Perkembangan teknologi mendorong sektor industri untuk lebih kreatif dalam membuat sebuah alat sederhana yang dapat membantu masyarakat dalam kehidupan sehari-hari sehingga dapat berguna bagi banyak orang dan berfungsi baik [24]. Arduino berfungsi membaca nilai pada sensor tegangan AC, sensor tegangan DC, LCD [25]. Energi merupakan bagian yang paling penting bag makhluk hidup untuk bisa terus bertahan hidup [26]. Security home adalah sebuah rumah yang didesain untuk menjaga kemanan rumah melalui perangkat keras maupun perangkat lunak untuk memberikan keamanan dari segi pintu, system alarm, detector gerak (passive infrared), detector api, gas, maupun air [27]. Operasi pembangkit tenaga listrik harus aman dan terpercaya [28]. Sumber energi fosil seperti minyak bumi, gas alam dan batubara akan bisa bertahan jika sumber energi terbarukan digunakan [29]. Rangkaian band pass filter adalah rangkaian yang mengizinkan lewat sinyal yang memiliki frekuensi pada rentang tertentu dan mengattenuasikan sinyal yang memiliki frekuensi di luar rentang tersebut [30]. Penggunaan kapasitor bank di industri misalnya sebagai alat kompensator faktor daya, memperbaiki drop tegangan pada ujung jaringan, atau kenaikan suhu dan arus pada penghantar bisa diperkecil dengan di pasang kapasitor [31].[32]yang sering digunakan adalah pentacene karena ketersediaannya dan kinerja divaisnya . Kemajuan teknologi yang pada masa sekarang ini terus mengalami perkembangan dan di ikuti oleh sebagian bahkan hampir semua kalangan [33]. Perkembangan Ilmu Pengetahuan dan Teknologi (IPTEK) yang semakin maju khususnya dibidang elektronika, memberi banyak kemudahan dalam penggunaan perangkat ataupun alat-alat yang berhubungan langsung dengan kebutuhan hidup manusia [34]. Whatsapp API dalam aplikasi elektronika jauh lebih menarik dibandingkan sistem SMS gateway yang sudah lama digunakan [35].

\section{METODE}

Minyak pelumas mesin atau yang lebih dikenal oli mesin memang banyak ragam dan 
RESISTOR (Elektronika Kendali Telekomunikasi Tenaga Listrik Komputer) Vol. 2 No. 2 e-ISSN : 2621-9700, p-ISSN : 2654-2684

macamnya. Bergantung jenis penggunaan mesin itu sendiri yang membutuhkan oli yang tepat untuk menambah atau mengawetkan usia pakai (life time) mesin. Semua jenis oli pada dasarnya sama. Yakni sebagai bahan pelumas agar mesin berjalan mulus dan bebas gangguan. Sekaligus berfungsi sebagai pendingin dan penyekat. Oli mengandung lapisanlapisan halus, berfungsi mencegah terjadinya benturan antar logam dengan logam komponen mesin seminimal mungkin, mencegah goresan atau keausan. Untuk beberapa keperluan tertentu, aplikasi khusus pada fungsi tertentu, oli dituntut memiliki sejumlah fungsi-fungsi tambahan. Mesin diesel misalnya, secara normal beroperasi pada kecepatan rendah tetapi memiliki temperatur yang lebih tinggi dibandingkan dengan mesin bensin. Mesin diesel juga memiliki kondisi kondusif yang lebih besar yang dapat menimbulkan oksidasi oli, penumpukan deposit dan perkaratan logam-logam bearing. Sebagai contoh di bawah ini adalah tipe Viskositas dan ambien temperatur dalam derajat Celcius yang biasa digunakan sebagai standar oli di berbagai negara/kawasan.

1. 5W-30 untuk cuaca dingin seperti di Swedia

2. 10W-30 untuk iklim sedang seperti di kawasan Inggris

3. 15W-30 untuk Cuaca panas seperti di kawasan Indonesia

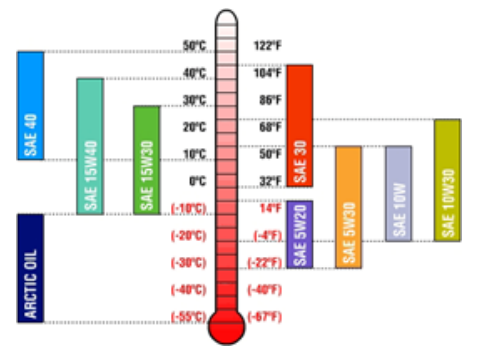

Gambar 1 Suhu berpengaruh terhadap kekentalan.

Pada perancangan "Sistem Pengingat Ganti Oli Berdasarkan Running Hours Mesin, Lama Waktu Pemakaian \& Kekentalan Oli Pada Mesin Wire Drawing Berbasis Raspberry Pi” memiliki 7 input yaitu sensor putaran mesin untuk membaca running hours, Pengukuran kekentalan oli dan 4 push button untuk pemilihan menu. 3 output yaitu LCD dan buzzer. Supaya dapat digunakan sebagai sensor, maka photodioda dibias reverse [36].

Pada menu pilihan terdapat 3 buah jenis oli yang dapat kita pilih sebagai set point pada oli yang akan kita pakai. Dengan menu pemilihan oli penggunaan oli sesuai dengan parameter yang sudah ditentukan. Jika salah satu dari ketiga parameter running hours mesin, lama waktu pemakaian dan

kekentalan sudah ada yang mencapai terlebih dahulu, maka buzzer akan berbunyi menandakan oli harus segera diganti

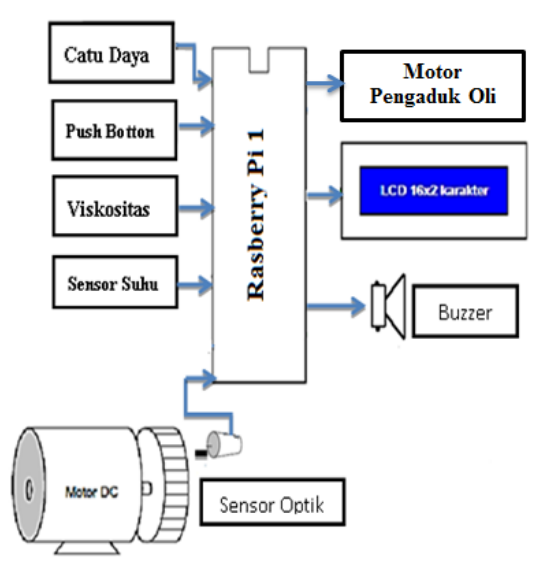

Gambar 2 Blok diagram sistem.

Perancangan adalah bagian yang paling dalam suatu pembuatan alat, karena pada bagian ini akan dilakukan realisasi dari suatu ide yang didukung oleh teori teori yang telah dijelaskan pada bab seblumnya. Dengan demikian akan dihasilkan sebuh alat yang diharapkan dapat mempunyai spesifikasi yang diinginkan. Selain itu, juga akan diketahui letak kesulitan yang dialami dalam pembuatan alat tersebut. Adapun Perancangan yang dibuat sebagai berikut

1. Perancangan simulator mesin

2. Perancangan pengaduk oli

3. Perancangan catu daya

4. Perancangan rangakaian sensor running hours

5. Perancangan sensor suhu

6. Perancangan sensor pembaca kekentalan

7. Rangkaian switch / push button

8. Perancangan proses pada sistem raspberry pi

9. Perancangan output rangkaian buzzer

10. Perancangan output rangkaian pengaduk oli

11. Perancangan output rangkaian LCD

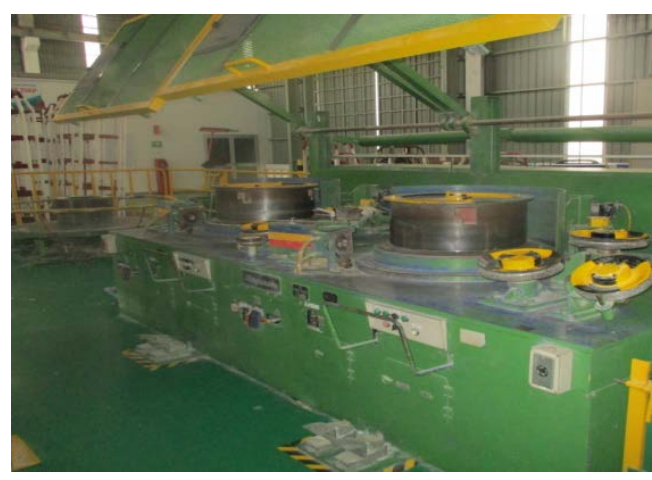

Gambar 3 Mesin wire drawing. 
RESISTOR (Elektronika Kendali Telekomunikasi Tenaga Listrik Komputer) Vol. 2 No. 2 e-ISSN : 2621-9700, p-ISSN : 2654-2684

Dalam pemasangan tanki pengaduk oli di pasangkan dengan level oli pada mesin, dengan tujuan agar mempermudah pengecekan level pada tanki pengaduk oli, tanki pengaduk oli dipasangkan di bagian dalam cover mesin, Pada pipa level oli dipasangkan $\mathrm{T}$ Neple Joint yang berfungsi sebagai penghubung level oli mesin dengan tanki pengaduk oli, pada tanki pengaduk oli juga dipasangkan pipa buangan udara yang dihubungkan dengan pipa level oli difungsikan untuk mengeluarkan udara agar tidak terjadi tekanan pada tanki pengaduk oli indicator level oli dengan tanki oli akan terisi sesuai dengan ketinggian level oli pada gearbox mesin drum blok wire.

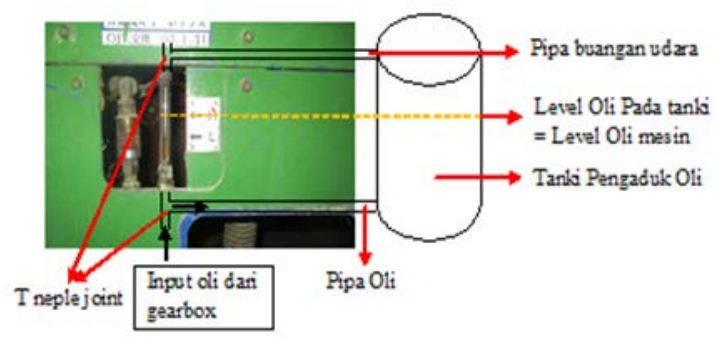

Gambar 4 Perancangan pemasangan pengaduk oli pada mesin wire drawing.

Pada pemasangan sensor pembaca running hours mesin pada mesin wire drawing digunakan proximity sensor sebagai pembaca atau mendeteksi logam pada plat besi yang diputarkan oleh shaft motor pada saat motor running atau mesin bekerja, hasil pembacaan proximity sensor akan menjadikan input pada raspberry pi 1 , untuk simulator mesin dipakai sensor photodiode sebagai pengganti proximity sensor.

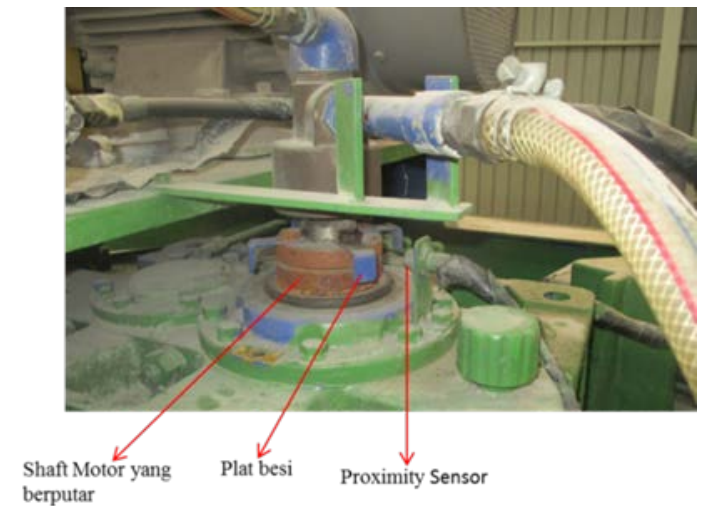

Gambar 5 Perancangan pemasangan sensor pembaca running hours mesin.

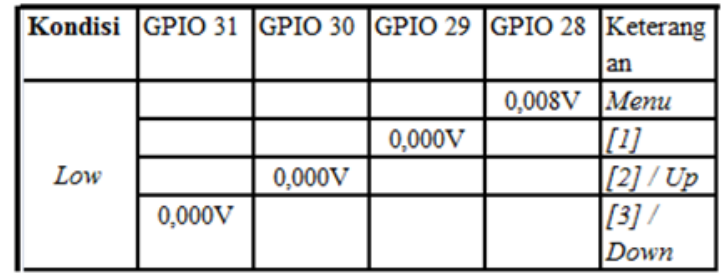

Gambar 6 Kondisi GPIO.

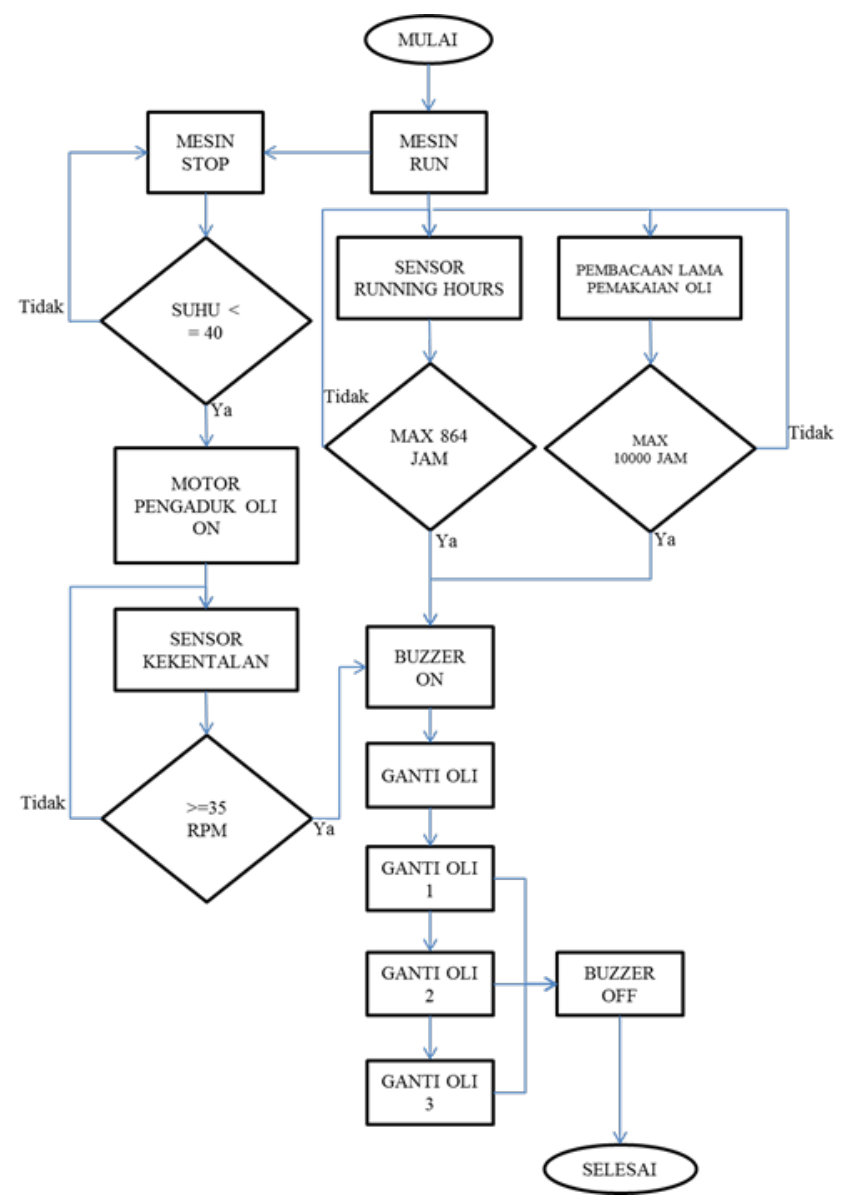

Gambar 7 Sistem oli.

\section{HASIL DAN PEMBAHASAN}

Dalam pengujian pada "Sistem Pengingat Ganti OLi Berdasarkan Running Hours Mesin, Lama Waktu Pemakaian \& Kekentalan Oli Pada Mesin Wire Drawing Berbasis Raspberry Pi" terdapat beberapa tahapan pengujian yang harus dilaksanankan yaitu pengujian terhadap power supply, pengujian LCD dan Push Botton, pengukuran Pada Sensor dan Sistem Raspberry pi 1

Tabel 1 Pengujian catu daya.

\begin{tabular}{|c|c|l|c|}
\hline $\begin{array}{c}\text { Vin } \\
\text { Trafo }\end{array}$ & $\begin{array}{c}\text { Vout } \\
\text { trafo }\end{array}$ & $\begin{array}{l}\text { Vin IC } \\
7805\end{array}$ & $\begin{array}{c}\text { Vin IC } \\
7805\end{array}$ \\
\hline 220vac & $9,50 \mathrm{Vdc}$ & $9.2 \mathrm{Vdc}$ & $4.92 \mathrm{Vdc}$ \\
\hline
\end{tabular}


RESISTOR (Elektronika Kendali Telekomunikasi Tenaga Listrik Komputer) Vol. 2 No. 2 e-ISSN : 2621-9700, p-ISSN : 2654-2684

Tabel 2 Pengujian LCD dan push button.

\begin{tabular}{|l|l|l|l|l|l|}
\hline Kondisi & GPIO 31 & GPIO 30 & GPIO 29 & GPIO 28 & $\begin{array}{l}\text { Keterang } \\
\text { an }\end{array}$ \\
\hline \multirow{5}{*}{ High } & & & & $4,975 \mathrm{~V}$ & Menu \\
\cline { 2 - 6 } & & & $4,970 \mathrm{~V}$ & & {$[1]$} \\
\cline { 2 - 6 } & $4,965 \mathrm{~V}$ & & & & $\begin{array}{l}{[3] /} \\
\text { Down }\end{array}$ \\
\hline
\end{tabular}

Pengukuran dilakukan untuk mengetahui nilai tegangan yang di hasilkan pada output sensor maupun output Raspberry pi 1.

Tabel 3 Pengukuran photodioda pada roda / drum blok mesin (putaran mesin), running hours mesin.

\begin{tabular}{|c|l|l|}
\hline Kondisi & GPIO 9 & Keterangan \\
\hline High & $4,850 \mathrm{~V}$ & ON \\
\hline Low & $0,605 \mathrm{~V}$ & OFF \\
\hline
\end{tabular}

Tabel 4 Pengukuran photodioda pada pengaduk (sensor kekentalan).

\begin{tabular}{|c|l|l|}
\hline Kondisi & GPIO 9 & Keterangan \\
\hline High & $4,850 \mathrm{~V}$ & ON \\
\hline Low & $0,605 \mathrm{~V}$ & OFF \\
\hline
\end{tabular}

Pengujian ini dilakukan dengan membandingkan pembacaan temperature pada oli antara DS18B20 dan thermometer infrared dengan cara mengukur kenaikan suhu

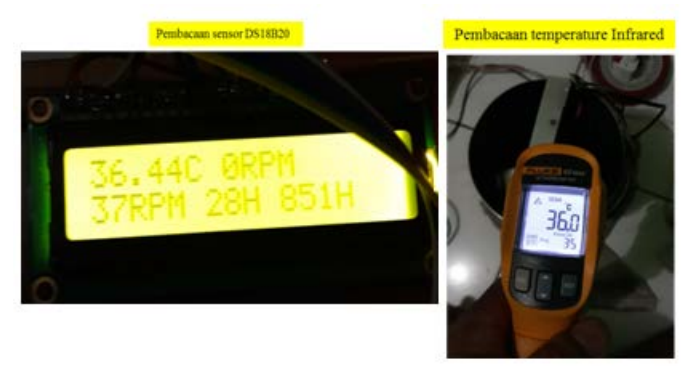

Gambar 8 Pembacaan suhu.

Tabel 5 Pengukuran perbandingan temperatur.

\begin{tabular}{|c|c|c|}
\hline \multicolumn{2}{|c|}{ Alat Ukur } & \\
\hline $\begin{array}{c}\text { DSB18B } \\
\mathbf{2 0}\end{array}$ & $\begin{array}{c}\text { Thermo } \\
\text { meter } \\
\text { infrared } \\
\text { FLUKE }\end{array}$ & $\begin{array}{c}\% \\
\text { Keberhasilan }\end{array}$ \\
\hline 35 & 35.5 & $98 \%$ \\
\hline 36 & 36.4 & $98 \%$ \\
\hline 37 & 37.5 & $98 \%$ \\
\hline 38 & 38.6 & $98 \%$ \\
\hline 39 & 39.3 & $99 \%$ \\
\hline 40 & 40.5 & $98 \%$ \\
\hline 41 & 41.5 & $98 \%$ \\
\hline 42 & 42.2 & $99 \%$ \\
\hline 43 & 43.5 & $98 \%$ \\
\hline 44 & 44.6 & $98 \%$ \\
\hline 45 & 45.5 & $98 \%$ \\
\hline
\end{tabular}

Pengujian ini dilakukan dengan cara mengambil data sample sebagai acuan nilai pada penetuan kekentalan oli. Sample yang di gunakan adalah oli yang sudah digunakan melebihi pemakaian 10000 hrs, \pm 8000 hrs, \pm 4000 hrs dan oli baru. Jenis oli yang di uji adalah jenis oli sintetis SAE 40 sebanyak 1 liter yang dituangkan kedalam tanki pengaduk oli. Kekentalan di ukur dengan cara menghitung banyaknya putaran pada pengaduk oli. Putaran pengaduk oli digerakan oleh motor 5vdc yang akan bekerja selama 20 detik, selama 20 detik akan didapat hasil pembacaan putaran dari pengaduk oli. Hasil pembacaan akan dikalikan 3.

Contoh: hasil pembacaan putaran pada pengaduk oli selama 20 detik $=11$ putaran. Maka, 60 detik $/ 20$ detik $=3$ sehingga 11 putaran x $3=33$ putaran per menit (RPM). Dari hasil pengamatan tersebut diperoleh data sebagai berikut:

Tabel 6 Pengukuran putaran pengaduk pada oli pemakaian 10000 jam.

\begin{tabular}{|c|c|c|c|c|c|c|c|}
\hline \multicolumn{8}{|c|}{ PENGUJIAN OLI PEMAKAIN 10000 Hrs (TIDAK LAYAK PAKAI) } \\
\hline \multirow[b]{2}{*}{ No } & \multirow[b]{2}{*}{ emperatu } & \multicolumn{5}{|c|}{ Putaran Pengaduk (RPM) } & \multirow[b]{2}{*}{ AvG } \\
\hline & & 1 & 2 & 3 & 4 & 5 & \\
\hline 1 & 29 & 33 & 33 & 33 & 33 & 33 & 33 \\
\hline 2 & 32 & 35 & 35 & 35 & 35 & 35 & 35 \\
\hline 3 & 33 & 35 & 35 & 35 & 35 & 35 & 35 \\
\hline 4 & 34 & 36 & 36 & 36 & 36 & 36 & 36 \\
\hline 5 & 35 & 36 & 36 & 36 & 36 & 36 & 36 \\
\hline 6 & 36 & 37 & 37 & 37 & 37 & 37 & 37 \\
\hline 7 & 37 & 37 & 37 & 37 & 37 & 37 & 37 \\
\hline 8 & 38 & 38 & 38 & 38 & 38 & 38 & 38 \\
\hline \multirow[t]{2}{*}{9} & 39 & 38 & 38 & 38 & 38 & 38 & 38 \\
\hline & & & & & & AVG & 36.11 \\
\hline
\end{tabular}

Tabel 7 Pengukuran putaran pengaduk pada oli pemakaian \pm 8000 jam. 
RESISTOR (Elektronika Kendali Telekomunikasi Tenaga Listrik Komputer) Vol. 2 No. 2 e-ISSN : 2621-9700, p-ISSN : 2654-2684

\begin{tabular}{|c|c|c|c|c|c|c|c|}
\hline \multicolumn{7}{|c|}{ PENGUJAN OLI PEMAKAIN $\pm \mathbf{8 0 0 0}$ Hrs } \\
\cline { 3 - 7 } No & emperatu & $\mathbf{1}$ & $\mathbf{2}$ & $\mathbf{3}$ & $\mathbf{4}$ & $\mathbf{5}$ & \multirow{2}{*}{ AVG } \\
\hline 1 & 29 & 33 & 33 & 33 & 33 & 33 & 33 \\
\hline 2 & 32 & 34 & 34 & 34 & 34 & 34 & 34 \\
\hline 3 & 33 & 35 & 35 & 35 & 35 & 35 & 35 \\
\hline 4 & 34 & 35 & 35 & 35 & 35 & 35 & 35 \\
\hline 5 & 35 & 35 & 35 & 35 & 35 & 35 & 35 \\
\hline 6 & 36 & 36 & 36 & 36 & 36 & 36 & 36 \\
\hline 7 & 37 & 36 & 36 & 36 & 36 & 36 & 36 \\
\hline 8 & 38 & 36 & 36 & 36 & 36 & 36 & 36 \\
\hline 9 & 39 & 37 & 37 & 37 & 37 & 37 & 37 \\
\hline
\end{tabular}

Tabel 8 Pengukuran putaran pengaduk pada oli pemakaian \pm 4000 jam.

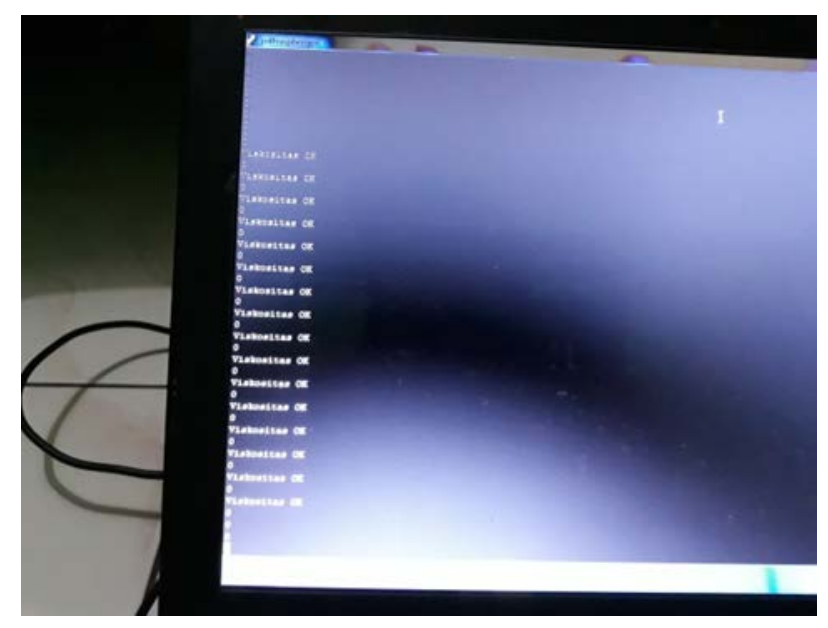

PENGUJIAN OLI PEMAKAIN $\pm 4000 \mathrm{Hrs}$

\begin{tabular}{|c|c|c|c|c|c|c|c|}
\hline \multirow[b]{2}{*}{ no } & \multirow[b]{2}{*}{ emperatu } & \multicolumn{5}{|c|}{ Putaran Pengaduk (RPM) } & \multirow[b]{2}{*}{ AVG } \\
\hline & & 1 & 2 & 3 & 4 & 5 & \\
\hline 1 & 29 & 33 & 33 & 33 & 33 & 33 & 32 \\
\hline 2 & 32 & 34 & 34 & 34 & 34 & 34 & 32 \\
\hline 3 & 33 & 34 & 34 & 34 & 34 & 34 & 33 \\
\hline 4 & 34 & 34 & 34 & 34 & 34 & 34 & 33 \\
\hline 5 & 35 & 34 & 34 & 34 & 34 & 34 & 34 \\
\hline 6 & 36 & 35 & 35 & 35 & 35 & 35 & 34 \\
\hline 7 & 37 & 35 & 35 & 35 & 35 & 35 & 34 \\
\hline 8 & 38 & 35 & 35 & 35 & 35 & 35 & 35 \\
\hline \multirow[t]{2}{*}{9} & 39 & 35 & 35 & 35 & 35 & 35 & 35 \\
\hline & & & & & & AVG & 33.56 \\
\hline
\end{tabular}

Gambar 10 Kekentalan OK.

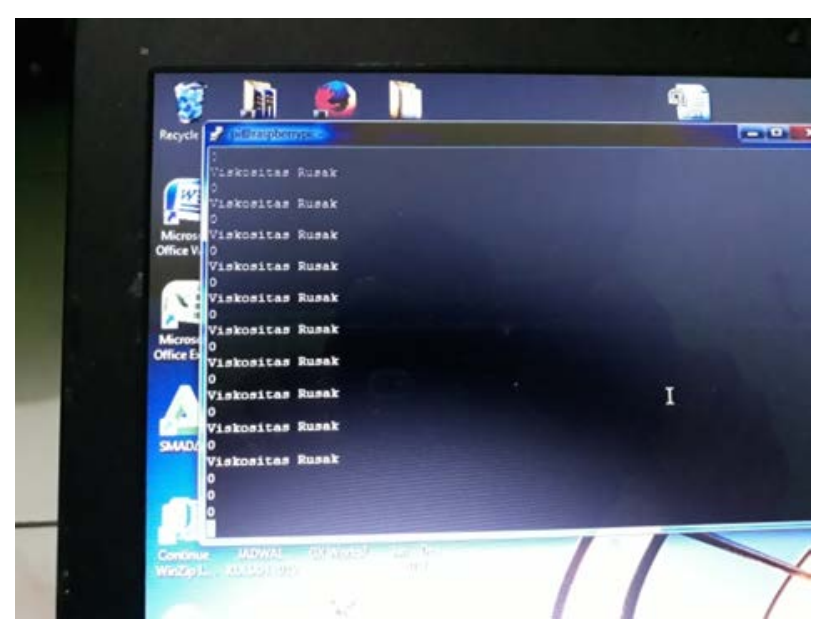

Gambar 11 Kekentalan rusak.

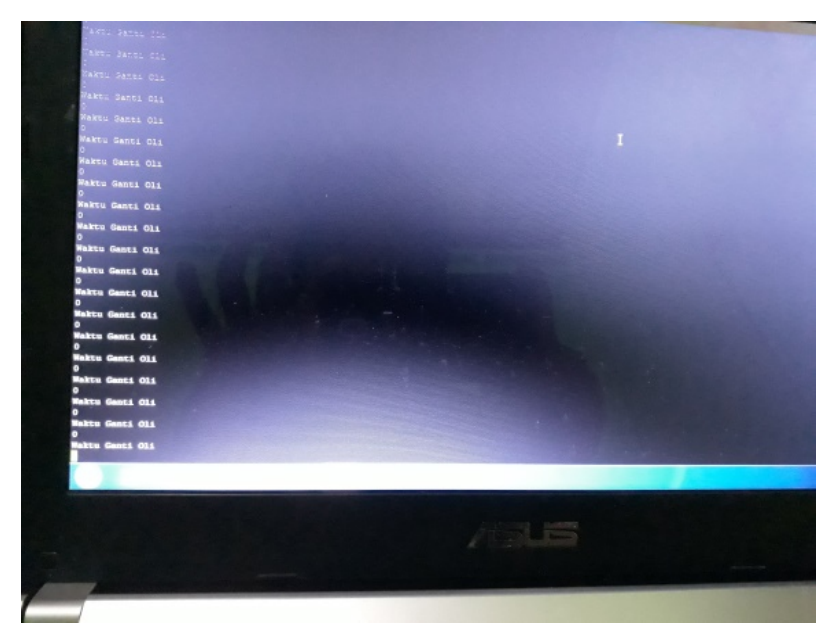

Gambar 12 Saat mengganti oli. 

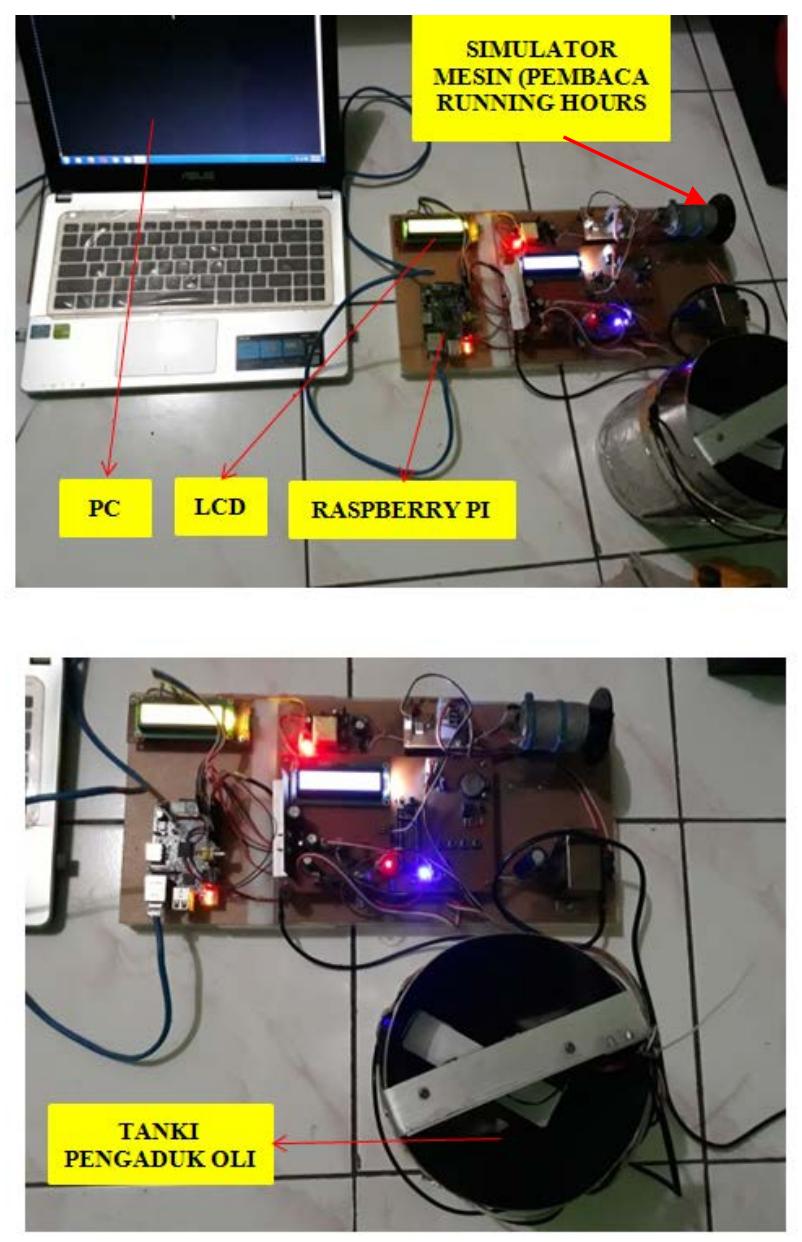

Gambar 13 Foto alat.

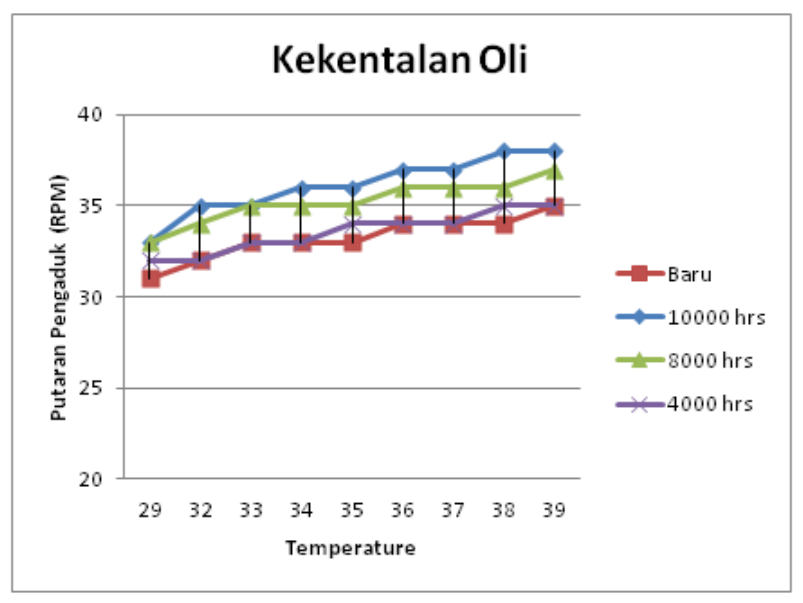

Gambar 14 Hasil pengujian oli.

\section{KESIMPULAN}

Setelah melakukan perancangan sistem, baik software maupun hardware terhadap "Sistem Pengingat Ganti Oli Berdasarkan Running Hours Mesin, Lama Waktu Pemakaian dan Kekentalan Oli Pada Mesin Wire Drawing Berbasis Raspberry Pi” maka dilakukan beberapa percobaan dan pengujian terhadap sistem sehingga dapat disimpulkan bahwa sistem dapat bekerja sesuai dengan yang diharapkan yaitu dapat menghitung running hours mesin produksi yang bersesuaian sehingga akan mengaktifkan buzzer sebagai tanda peringatan bahwa oli harus sesegera mungkin diganti agar tidak menimbulkan kerugian yang tidak diharapkan, dapat menghitung lamanya waktu pemakaian dari oli diganti sampai dengan waktu yang telah ditentukan sehingga mengaktifkan buzzer sebagai tanda oli harus segera diganti, dapat menghitung banyak putaran mesin pada pengaduk oli sebagai pembanding kekentalan oli yang bersesuaian sehingga akan mengaktifkan buzzer sebagai tanda oli harus segera diganti, pada LCD dapat menampilkan tulisan, sehingga segalanya dapat dengan mudah diketahui sesuai dengan progam yang telah di buat, sistem raspberry pi 1 sebagai otak kerja utama dapat berkerja dengan baik sesuai dengan progam yang telah dibuat sehingga sistem dapat bekerja dengan baik, pada pembacaan kekentalan belum dapat terkalibrasi, tetapi alat dapat membantu maintenance untuk merawat mesin wire drawing. Adapun berbagai saran yang dapat dipergunakan sebagai bahan rujukan ataupun masukan jika alat ini ingin dikembangkan lebih lanjut demi kesempurnaan teknologi dan agar terciptanya suatu sistem yang stabil maupun handal terhadap berbagai gangguan, maka peneliti memberikan beberapa saran masukan antara lain Sistem Pengingat Ganti Oli Berdasarkan Running Hours Mesin, Lama Waktu Pemakaian \& Kekentalan Oli Pada Mesin Wire Drawing Berbasis Raspberry Pi” dapat ditambahkan dengan sistem pengingat melalui pesan singkat dan IOT (internet of think), sehingga ketika kendaraan tidak sedang di pakai oleh pemilik maka pengingat pergantian oli akan tetap diketahui oleh pemilik dan dapat di monitor dari jarak jauh dan "Sistem Pengingat Ganti Oli Berdasarkan Running Hours Mesin, Lama Waktu Pemakaian \& Kekentalan Oli Pada Mesin Wire Drawing Berbasis Raspberry Pi" dapat ditambahkan dengan sistem pengingat water coolant mesin atau oli sehingga selain oli yang dikontrol, water coolant juga dijaga agar dalam jumlah yang stabil untuk membebantu mendinginkan mesin sehingga mesin produksi akan semakin bertambah lifetimenya dari kerusakankerusakan akibat mesin panas.

\section{DAFTAR PUSTAKA}

[1] J. M. Selig, Introductory robotics. 2017.

[2] R. Sulistyowati and D. D. Febriantoro, "Perancangan prototype sistem kontrol dan monitoring pembatas daya listrik berbasis mikrokontroler,” Jurnal IPTEK, vol. 16, no. 1, 2012. 
RESISTOR (Elektronika Kendali Telekomunikasi Tenaga Listrik Komputer) Vol. 2 No. 2 e-ISSN : 2621-9700, p-ISSN : 2654-2684

[3] T. Febrianto, "RANCANG BANGUN ALAT UJI KELAYAKAN PELUMAS KENDARAAN BERMOTOR BERBASIS MIKROKONTROLER,” Universitas Negeri Semarang, 2012.

[4] P. G. Chamdareno, E. Nuryanto, and E. Dermawan, "Perencanaan Sistem Pembangkit Listrik Hybrid (Panel Surya dan Diesel Generator) pada Kapal KM. Kelud,” RESISTOR (elektRonika kEndali telekomunikaSI tenaga liSTrik kOmputeR), vol. 2, no. 1, pp. 59-64, 2019.

[5] F. Fadliondi, P. G. Chamdareno, and H. Isyanto, "Perbandingan Pemahaman tentang Instalasi Listrik Rumah Tinggal antara Sebelum dan Sesudah Mengikuti Pelatihan,” Jurnal Pengabdian Masyarakat Teknik, vol. 1, no. 1, pp. 1-11, 2018.

[6] S. Sriyono and B. Budiyanto, "Studi Penggunaan DC Nanogrid dengan Sumber Photovoltaic pada Beban Bertegangan dibawah Dua Puluh Empat Volt,” RESISTOR (elektRonika kEndali telekomunikaSI tenaga liSTrik kOmputeR), vol. 2, no. 1, pp. 1-6, 2019.

[7] E. B. Prasetya, "Aplikasi Manajemen Proyek Konstruksi dengan Metode Critical Path dan Earned Value Management," RESISTOR (elektRonika kEndali telekomunikaSI tenaga liSTrik kOmputeR), vol. 1, no. 2, pp. 53-68, 2018.

[8] R. Samsinar and W. Wiyono, "Studi Keandalan Rekonfigurasi Jaringan Program Zero Down Time (Zdt) di Kawasan Sudirman Central Business Distric (Scbd) Menggunakan Software ETAP 12.6,” RESISTOR (elektRonika kEndali telekomunikaSI tenaga liSTrik kOmputeR), vol. 2, no. 1, pp. 65-72, 2019.

[9] H. Muchtar and R. Apriadi, "Implementasi Pengenalan Wajah Pada Sistem Penguncian Rumah Dengan Metode Template Matching Menggunakan Open Source Computer Vision Library (Opencv)," RESISTOR (elektRonika kEndali telekomunikaSI tenaga liSTrik kOmputeR), vol. 2, no. 1, pp. 39-42, 2019.

[10] D. Almanda and B. Kusuma, "Audit Energi Listrik Pabrik,” RESISTOR (elektRonika kEndali telekomunikaSI tenaga liSTrik kOmputeR), vol. 1, no. 1, 2018.

[11] P. G. Chamdareno, B. Budiyanto, F. Fadliondi, and H. Isyanto, "STUDI EKSPERIMEN
TERHADAP PANEL SURYA DAN INVERTER,” Prosiding Semnastek, 2017.

[12] F. Fadliondi and B. Budiyanto, "Transistor Efek Medan Berbasis Semikonduktor Organik Pentacene untuk Sensor Kelembaban,” Jurnal Nasional Teknik Elektro dan Teknologi Informasi, vol. 6, no. 2, pp. 204-209, 2017.

[13] D. Almanda and D. Bhaskara, "Studi Pemilihan Sistem Pendingin pada Panel Surya Menggunakan Water Cooler, Air Mineral dan Air Laut," RESISTOR (elektRonika kEndali telekomunikaSI tenaga liSTrik kOmputeR), vol. 1, no. 2, pp. 43-52, 2018.

[14] H. Isyanto, A. Solikhin, and W. Ibrahim, "Perancangan dan Implementasi Security System pada Sepeda Motor Menggunakan RFID Sensor Berbasis Raspberry Pi,” RESISTOR (elektRonika kEndali telekomunikaSI tenaga liSTrik kOmputeR), vol. 2, no. 1, pp. 29-38, 2019.

[15] L. Halim and C. F. Naa, "Desain Sistem Pendayaan Energi Listrik pada Rumah Kaca Pintar dengan Menggunakan Pembangkit Listrik Tenaga Surya,” RESISTOR (elektRonika kEndali telekomunikaSI tenaga liSTrik kOmputeR), vol. 2, no. 1, pp. 43-50, 2019.

[16] F. Fadliondi, B. Budiyanto, and H. Isyanto, "SIMULASI KARAKTERISTIK LISTRIK DARI SEL SURYA YANG TERHUBUNG SECARA PARALEL DAN PENGUJIANNYA SECARA EKSPERIMEN,” Prosiding Semnastek, 2018.

[17] P. G. Chamdareno and H. Hilal, "Analisa Pembangkit Listrik Tenaga Hybrid PLTDPLTS di Pulau Tunda Serang Banten,” RESISTOR (elektRonika kEndali telekomunikaSI tenaga liSTrik kOmputeR), vol. 1, no. 1, pp. 35-42, 2018.

[18] B. Budiyanto and F. Fadliondi, "The Improvement of Solar Cell Output Power Using Cooling and Reflection from Mirror,” International Journal of Power Electronics and Drive Systems, vol. 8, no. 3, p. 1320, 2017.

[19] M. H. Widianto, “Alat Pengatur Suhu Otomatis pada Ruangan Produksi Textile Spining Berbasis Mikrokontroler Atmega32 di PT. San Star Manunggal,” RESISTOR (elektRonika kEndali telekomunikaSI tenaga liSTrik kOmputeR), vol. 2, no. 1, pp. 51-58, 2019. 
RESISTOR (Elektronika Kendali Telekomunikasi Tenaga Listrik Komputer) Vol. 2 No. 2 e-ISSN : 2621-9700, p-ISSN : 2654-2684

[20] F. Fadliondi, H. Isyanto, and P. Gagani, "Pengaruh Ketebalan Lapisan Isolator Sio2 terhadap Mobilitas Lubang dari Transistor Efek Medan Organik Pentacene,” Prosiding Semnastek, 2016.

[21] F. Fadliondi, N. Hasanah, and A. Asriyadi, "Simulasi dan Pembuatan Rangkaian Penyearah Gelombang Penuh dengan Trafo Center Tapped dengan Memakai Perangkat Lunak LT SPICE,” RESISTOR (elektRonika kEndali telekomunikaSI tenaga liSTrik kOmputeR), vol. 2, no. 1, pp. 23-28, 2019.

[22] H. Isyanto, F. Fadliondi, and B. Budiyanto, "STUDI SIMULASI DAN EKSPERIMEN PADA KARAKTERISTIK LISTRIK SEL SURYA YANG TERHUBUNG SECARA SERI,” Prosiding Semnastek, 2018.

[23] F. Fadliondi, H. Isyanto, and P. G. Chamdareno, "The comparison of organic field effect transistor (OFET) structures," in 2017 2nd International Conference on Frontiers of Sensors Technologies (ICFST), 2017, pp. 6-9.

[24] M. H. Widianto, "Pengaplikasian Sensor Hujan dan LDR untuk Lampu Mobil Otomatis Berbasis Arduino Uno," RESISTOR (elektRonika kEndali telekomunikaSI tenaga liSTrik kOmputeR), vol. 1, no. 2, 2018.

[25] H. Muchtar and R. Sumanjaya, "Control Switch Otomatis pada Tegangan Energi Alternatif dan Tegangan Sumber PLN Menggunakan Raspberry Pi,” RESISTOR (elektRonika kEndali telekomunikaSI tenaga liSTrik kOmputeR), vol. 1, no. 2, 2018.

[26] H. Isyanto, B. Budiyanto, F. Fadliondi, and P. G. Chamdareno, "Pendingin Untuk Peningkatan Daya Keluaran Panel Surya," Prosiding Semnastek, 2017.

[27] H. Isyanto and M. Syahrullah, "Perancangan Security Home (Keamanan pada Rumah) Menggunakan Mikrokontroller Berbasis SMS (Short Message Service)," RESISTOR (elektRonika kEndali telekomunikaSI tenaga liSTrik kOmputeR), vol. 1, no. 2, pp. 85-96, 2018.

[28] R. Samsinar, N. Purnomo, and D. Almanda, "Studi Kelayakan Core Iron Stator Dengan Metode Loop/ELCID Test,” RESISTOR (elektRonika kEndali telekomunikaSI tenaga liSTrik kOmputeR), vol. 1, no. 2, pp. 103-116, 2018.
[29] F. Fadliondi, H. Isyanto, and B. Budiyanto, "Bypass Diodes for Improving Solar Panel Performance," International Journal of Electrical and Computer Engineering, vol. 8, no. 5, p. 2703, 2018.

[30] F. Fadliondi and A. Asriyadi, "Eksperimen dan Simulasi Rangkaian Band Pass Filter (BPF) dengan Resistor dan Kapasitor," RESISTOR (elektRonika kEndali telekomunikaSI tenaga liSTrik kOmputeR), vol. 1, no. 2, pp. 69-78, 2018.

[31] D. Almanda and N. Majid, "Studi Analisa Penyebab Kerusakan Kapasitor Bank Sub Station Welding di PT. Astra Daihatsu Motor,” RESISTOR (elektRonika kEndali telekomunikaSI tenaga liSTrik kOmputeR), vol. 2, no. 1, pp. 7-14, 2019.

[32] F. Fadliondi, M. Kunta Biddinika, and S. I. Omi, "The Humidity Dependence of Pentacene Organic Metal-Oxide-Semiconductor FieldEffect Transistor.,” Telkomnika, vol. 15, no. 2, 2017.

[33] H. Isyanto and D. Arsito, "Sistem Pengaman Rumah dan Peringatan Dini Kebakaran Berbasis SMS dengan Menggunakan Raspberry Pi,” RESISTOR (elektRonika kEndali telekomunikaSI tenaga liSTrik kOmputeR), vol. 1, no. 1, pp. 13-24, 2018.

[34] R. W. Simanjuntak, "Rancang Bangun/Prototype Alat Pengukur Kekentalan (Viskositas) Zat cair Berbasis Mikrokontroller ATMega328 Dengan Interface Android Menggunakan Komunikasi Bluetooth,” Politeknik Negeri Medan, 2014.

[35] D. Kurniawan, Membangun Aplikasi Elektronika dengan Raspberry Pi 2 dan. Elex Media Komputindo, 2016.

[36] K. Anam and W. Cahyadi, "Prototype Alat Pengukur Kekentalan Cairan Dengan Interface Visual Basic Menggunakan Komunikasi Bluetooth Hc-05 Berbasis Arduino.” 
RESISTOR (Elektronika Kendali Telekomunikasi Tenaga Listrik Komputer) Vol. 2 No. 2 e-ISSN : 2621-9700, p-ISSN : 2654-2684 